\title{
Personality Variables in Prediction of Control over Seizures in Patients with Partial Epilepsies
}

\author{
Vladimir V Kalinin*, Anna A Zemlyanaya, Elena V Zheleznova and Lyudmila V Sokolova
}

Department of Brain Organic Disorders and Epilepsy, Moscow research Institute, Psychiatry of Ministry of Health and Social Development, Russia

\begin{abstract}
The current study has been carried out in order to evaluate the possible relationship between premorbid personality constructs with therapeutic remission and seizures reduction under antiepileptic treatment in patients with partial forms of epilepsy. One hundred and three patients were included into study. There were 33 men and 70 women. The Munich Personality Test and Toronto Alexithymia Scale (TAS-26) have been used for the assessment of premorbid personality in patients. Product moment correlation and multiple forward stepwise regression were used for the analysis of interrelationship between independent variables (personality constructs) and dependent variables of therapeutic remission and percentage in seizures reduction. Obtained results have shown the favorable prognostic significance of Neuroticism, Extraversion, Frustration Tolerance for the percentage of sum of all partial seizures reduction and for sensory partial and motor partial seizures reduction. On the other hand, alexithymia correlated negatively with length of remission and percentage of all seizures reduction.
\end{abstract}

Keywords: Partial epilepsy; Therapeutic remission; Seizures reduction; Premorbid personality constructs; Alexithymia; Neuroticism; Extraversion; Frustration tolerance; Prediction of therapeutic response

\section{Introduction}

The control over seizures or at least reduction in their frequency is thought to be the principal aim in the treatment of patients with epilepsy. Nevertheless, the numerous data exist that at least $25-40 \%$ patients with primary diagnosed epilepsy are resistant to antiepileptic drugs [1-14]. In such cases the mode of "probes and errors" prevails in the treatment strategy, and the choice of any new antiepileptic drug (AED) depends mainly on the previous experience of physicians and so-called elaborated standards of antiepileptic drugs use.

The signs differentiating the patients in relation to their drug response before the treatment are rather scarce and controversial. Nevertheless, the general opinion exists that symptomatic partial forms of epilepsies, especially of traumatic origin and forms with cognitive deterioration (intelligence deficiency), early age at onset and concomitant psychotic disorders (i.e. depression), and status epilepticus, as a rule, are characterized by unfavorable course and poor response to drug treatment $[1-3,15]$. Most of these mentioned factors concern the so-called localized-related forms of epilepsy $[5,8,15,16]$.

Much less is known about the certain predictors of reduction of concrete semiotics seizures, although that $a$ priori could help clinicians to foresee the treatment efficacy of concrete antiepileptic drug. It concerns mostly patients with partial forms of epilepsy which are characterized by different seizures semiotics and uncertain therapeutic outcome.

The data on significance of definite clinical signs, neurobioloical and personality features, in particular, in prediction of control over seizures are too scarce that couldn't use them in every day epileptology practice. Nonetheless, in one of our previous work we have shown the role of handedness, focus laterality, gender and epilepsy forms and their interactions in predicting the remission length and seizures reduction irrespective their semiotics [17].

The role of pre-morbid personality features for the prediction of control over seizures results in epilepsy has not been elucidated yet, although in psychiatry such approach has been elaborated many years ago and has proved its competence and efficacy. It concerns mostly the pre-morbid personality structures in predicting the efficacy of antidepressant drugs in depression and antipsychotics in schizophrenia [18-21]. Nevertheless, in epileptology the concrete data on the significance of pre-morbid personality for this purpose are practically absent. Every personality may be regarded as constellation of several vectors (constructs) that depends on the genetic predisposition and environment factors interaction [18-22]. The principal aim of the current study was to find any possible personality variables, which potentially could be used as predictors of remission length and seizures reduction in patients with partial epilepsies. The analysis of concrete AED efficacy and comparison of different drugs response have not been intentionally included in the current study since the primary focus has been concentrated on non-pharmacological predictors of treatment response.

The corner stone of the current pilot study was hypothesis, that some certain personality traits may predispose the control over seizures concerning the different type of seizures and by that may be used for prediction purposes.

\section{Material and Methods}

The study has been carried out on 103 patients with epilepsy. Among all studied patients were 33 men and 70 women. The diagnosis of symptomatic epilepsy was set in 40 patients, the diagnosis of cryptogenic form -in 54 patients, and the diagnosis of idiopathic temporal lobe epilepsy - in 9 patients. The focus laterality was detected strictly by visual EEG-method, and data on ictal semiotics have not been taken into account. The left-sided foci were detected in 48 patients (12 men and 36 women), the right-sided foci - in 55 patients ( 22 men and 33 women).

${ }^{*}$ Corresponding author: Vladimir V. Kalinin, Department of Brain Organic Disorders and Epilepsy, Moscow research Institute, Psychiatry of Ministry of Health and Social Development, Russia; E-mail: doct.kalinin@mail.ru

Received August 05, 2014; Accepted December 30, 2014; Published January 10,2015

Citation: Kalinin VV, Zemlyanaya AA, Zheleznova EV, Sokolova LV (2015) Personality Variables in Prediction of Control over Seizures in Patients with Partial Epilepsies. Int J Neurorehabilitation 2: 137. doi:10.4172/2376-0281.1000137

Copyright: (c) 2015 Kalinin VV, et al. This is an open-access article distributed under the terms of the Creative Commons Attribution License, which permits unrestricted use, distribution, and reproduction in any medium, provided the original author and source are credited. 
The all principal characteristics of studied patients are included into Table 1.

The several principle variables depicting the results of treatment with AEDs were used in the current study. These variables include the length of therapeutic remission on the concrete AED (in months), the per cent in all seizures reduction during one year of treatment and the per cent of reduction of seizures of different semiotics. The duration of therapeutic remissions was obtained from diaries of patients. The percentage in reduction of all type seizures was calculated by dividing the amount of remained seizures after one year treatment by number of seizures per year before the treatment.

All patients have been treated by monotherapy including one of next AEDs: Carbamazepine (43 patients), Valproates (42 patients), Lamotridgine (4 patients), Topiramate (14 patients) and Levetiracetam (5 patients).

For assessment of the premorbid personality features the Munich Personality Test (MPT) has been used [20-22]. This test has been elaborated about 25 years ago by Zerssen et al. [22] and has proved its validity in the assessment of pre-morbid structure in different diagnostic categories of mental disorders. This test represents the formalized quantitative scores of different personality constructs which have been known since the classical works by E.Kretschmer, H.Eysenck and A.Elllis.

The MPT represents a self-rating questionnaire, and includes 51 questions depicting the different personality traits. The patients have filled in all rating scales themselves, and after that the obtained raw data have been transformed into six constructs in line with specific structure of scales. These constructs include Extraversion, Neuroticism, Rigidity, Frustration Tolerance, Tendencies to Isolation and Esoteric Tendency. The last two constructs form Schizoidia scale [22]. The other two control scales of MPT (Orientation towards Social Norms and Motivation) were not included in the final analysis.

\begin{tabular}{|c|c|c|}
\hline Item & Data & \\
\hline \multirow{2}{*}{ Number of patients } & \multicolumn{2}{|l|}{103} \\
\hline & Male 33 & Female 70 \\
\hline Age, years, mean (SD) & \multicolumn{2}{|l|}{$30,05(8,79)$} \\
\hline Seizure onset, years, mean (SD) & \multicolumn{2}{|l|}{$14,94(10,57)$} \\
\hline Duration of epilepsy, years, mean (SD) & \multicolumn{2}{|l|}{$14,69(9,64)$} \\
\hline Type of epilepsy & \\
\hline Frontal lobe, n (\%) & \multicolumn{2}{|l|}{$38(36,8)$} \\
\hline Temporal lobe, n (\%) & \multicolumn{2}{|l|}{$58(56,4)$} \\
\hline Multifocal, n (\%) & \multicolumn{2}{|l|}{$7(6,8)$} \\
\hline Form of epilepsy & \\
\hline Cryptogenic, n (\%) & \multicolumn{2}{|l|}{$63(61,2)$} \\
\hline Symptomatic, n (\%) & \multicolumn{2}{|l|}{$40(38,8)$} \\
\hline Focus laterality & \multicolumn{2}{|l|}{$48(46,6)$} \\
\hline Left-sided focus, n (\%) & Male 12 & Female 36 \\
\hline Right-sided focus, n (\%) & \multicolumn{2}{|l|}{$55(53,4)$} \\
\hline & Male 22 & Female 33 \\
\hline \multicolumn{3}{|l|}{ Antiepileptic treatment } \\
\hline Carbamazepine, n (\%) & \multicolumn{2}{|l|}{$43(41,7)$} \\
\hline Valproates, n (\%) & \multicolumn{2}{|l|}{$42(39,2)$} \\
\hline Lamotrigine, n (\%) & \multicolumn{2}{|l|}{$4(3,8)$} \\
\hline Topiramate, n (\%) & \multicolumn{2}{|l|}{$14(13,6)$} \\
\hline Levetiracetam, n (\%) & \multicolumn{2}{|l|}{$5(1,7)$} \\
\hline
\end{tabular}

Table 1: Main characteristics of studied patients.
Extraversion and Neuroticism constructs are derived from Eysenck and Eysenck concepts [23]. Rigidity is quite similar to construct of Typus melancholicus proposed by Tellenbach [24], while Tendency to Isolation and Esoteric Tendency are based on Kretschmer's classical study on relationships between constitution and personality [25]. Frustration tolerance refers to resiliency or stress coping strategy.

Along with MPT the Toronto Alexithymia Scale (TAS-26) [26,27] was explored for assessment of alexithymia, which, on the other hand, represents a relatively novel personality construction, and the term itself has been coined in 1972 by Sifneos [26,27]. The principal features of alexithymia include an inability to describe and to verbalize the emotional (affective) states, difficulties in discrimination of emotions and sensations, poverty of imagination and fantasies, and a special type of thought processes directed to the nearest surrounding of person. Such mode of thinking has got termed as Pensěe opěratoire [26,27].

Alexithymia is thought to be explained in terms of neuropsychology as result of transfer blockade between two hemispheres in the corpus callosum. Such model supposes that sensations originated from the right hemisphere can't pass to the left hemisphere and by that remains unrecognized by person $[28,29]$.

TAS- 26 consists of 26 items, and each item can be scored in points from 1 to 5 . The global alexithymia score in TAS-26 may be expressed from 26 to 130 points [27]. All patients whose global TAS-26 score exceeds 74 points were regarded as alexithymic persons. The mean average of TAS-26 score in non-alexithymic group $(\mathrm{N}=78)$ was $58,5+-$ 11,5 , and in alexithymic group $(\mathrm{N}=22)$ was $80,0+-4,8$ points.

\section{Statistics}

All data were statistically processed by SPSS program (11-th version) on personal computer. On the first step the product moment correlation analysis between different pre-morbid characteristics and the variables of treatment efficacy for each type of seizure and total sum of all seizures was performed. For these purposes a percentage of seizures reduction of each seizure semiotics and sum of all seizures was used. In addition the correlation between length of therapeutic remission and different pre-morbid traits has also been calculated.

On the next step the multiple stepwise regression analysis has been used in order to find the significant relationships between different constellations of premorbid personality traits, since every person has several vectors of different personality features which can interact between each with other [18-21]. In this line the MPT and Toronto Alexithymia scale data have been used as independent variables, while data on the length of remission and percentage in seizures reduction for each type and sum of all seizure types were regarded as dependent variables. Only statistically significant relationships on level below $\mathrm{p}<0,05$ were analyzed in line with recommendation of modern handbooks on medical statistics $[30,31]$.

\section{Results}

The main results are listed in the Tables 2 and 3. The Table 2 contains the data on correlations between different premorbid personality features, on one hand, and the variables of length of remission and percentage of different seizure reduction, on the other hand. As can be seen from this table the several statistically significant connections have been obtained.

Thus, alexithymia score correlated negatively as with remission length $(\mathrm{r}=-0,22 ; \mathrm{p}=0,039)$, as with percentage of all seizure reduction $(\mathrm{r}=-0,22 ; \mathrm{p}=0,031)$. It implies that high degree of alexithymia in 


\begin{tabular}{|c|c|c|c|c|c|c|c|}
\hline Variables & Alexithym. & Extrav. & Neurot. & Frust.Tol. & Rigidity & Tend.Isol. & Esot.Tend. \\
\hline Length of Remission & $\begin{array}{c}r=-0,22 \\
(p=0,039 ; n=103)\end{array}$ & $r=0,14$ & $r=-0,07$ & $r=0,14$ & $r=0,07$ & $r=0,06$ & $r=0,04$ \\
\hline \% Seizure Red.(All) & $\begin{array}{c}r=-0,22 \\
(p=0,031 ; n=103)\end{array}$ & $r=0,12$ & $r=0,02$ & $r=0,15$ & $r=-0,02$ & $r=-0,08$ & $r=-0,02$ \\
\hline \% PGTC Red. & $r=-0,25$ & $r=0,08$ & $r=-0,25$ & $r=0,34$ & $r=-0,01$ & $r=-0,03$ & $r=-0,25$ \\
\hline$\%$ SGTC Red. & $r=-0,10$ & $r=-0,01$ & $r=-0,06$ & $r=-0,03$ & $r=-0,13$ & $r=-0,07$ & $r=-0,08$ \\
\hline $\begin{array}{l}\text { \% All } \\
\text { Part.Red. }\end{array}$ & $r=-0,08$ & $r=0,15$ & $\begin{array}{c}r=0,40 \\
(p=0,002 ; n=60)\end{array}$ & $r=-0,02$ & $r=-0,02$ & $r=-0,02$ & $r=-0,09$ \\
\hline $\begin{array}{l}\text { \% Sens. } \\
\text { Part.Red. }\end{array}$ & $r=-0,16$ & $r=0,19$ & $\begin{array}{c}r=0,46 \\
(p=0,009 ; n=41)\end{array}$ & $r=-0,20$ & $r=0,09$ & $r=0,07$ & $r=-0,16$ \\
\hline \% Motor. Part.Red. & $r=0,09$ & $r=0,10$ & $r=0,13$ & $\begin{array}{c}r=0,45 \\
(p=0,042 ; n=21)\end{array}$ & $r=-0,15$ & $r=-0,17$ & $r=0,10$ \\
\hline $\begin{array}{l}\% \text { CPS } \\
\text { Red. }\end{array}$ & $r=-0,16$ & $r=0,10$ & $r=-0,05$ & $r=-0,02$ & $r=-0,18$ & $r=0,05$ & $r=0,06$ \\
\hline $\begin{array}{l}\text { \% Myoclon. } \\
\text { Red. }\end{array}$ & $r=-0,27$ & $r=-0,04$ & $r=0,06$ & $r=0,05$ & $r=-0,06$ & $r=-0,07$ & $r=0,17$ \\
\hline
\end{tabular}

Note: Statistically significant values of Pearson product moment correlations are marked in bold.

Table 2: Results of product moment correlations between premorbid personality constructs and results of treatment.

\begin{tabular}{|c|c|c|c|}
\hline Items & Selected premorbid personality constructs & $\mathbf{R}$ & $\mathbf{R}^{2}$ \\
\hline Length of Remission & -0,25 Alex.+0,115 Tend. Isol. & 0,25 & 0,07 \\
\hline \% Seizure Red.(All) & $-0,22$ Alex. & 0,22 & 0,05 \\
\hline \% PGTC Red. & 0,623 Frust.Tol.- 0,460 Extr. & 0,50 & 0,25 \\
\hline \% SGTC Red. & -0,32 Rigid.- 0,17 Alex. & 0,33 & 0,11 \\
\hline $\begin{array}{l}\% \text { All } \\
\text { Part.Red. }\end{array}$ & 0,509 Neurot.+0,254 Extr.-0,190 Esot.Tend. & 0,51 & 0,26 \\
\hline $\begin{array}{l}\% \text { Sens. } \\
\text { Part.Red. }\end{array}$ & 0,612 Neurot.+0,351 Extr.-0,28 Alex.-0,25 Frus.Tol.-0,18 Esot. Tend.-0,15 Tend. Isol. & 0,68 & 0,46 \\
\hline$\%$ Motor. Part.Red. & 0,880 Frust. Tol. + 0,562 Esot. Tend & 0,76 & 0,57 \\
\hline $\begin{array}{l}\% \text { CPS } \\
\text { Red. }\end{array}$ & -0,25 Rigid.-0,23 Alex. & 0,29 & 0,08 \\
\hline $\begin{array}{l}\% \text { Myoclon. } \\
\text { Red. }\end{array}$ & No constructs were included & 0,00 & 0,00 \\
\hline
\end{tabular}

Notes: The variables of seizures reduction and the length of remission were dependent, while premorbid personality constructs were independent. Statistically significant values of multiple coefficients of correlation $(R)$ are marked in bold.

$R$ - The multiple correlations co-efficient

$R^{2}$ - The mutual variance between independent and dependent variables.

Table 3: Results of regression analysis between premorbid personality constructs and results of treatment.

patients with TLE determines the shorter remission duration and lower reduction of all seizures after treatment. Quite the contrary, the low alexithymia level predisposes to favorable treatment results and to long remission.

The Neuroticism score correlated positively both with percentage of all partial seizures reduction $(\mathrm{r}=0,40 ; \mathrm{n}=0,002)$ and sensory partial seizure reduction $(r=0,46 ; p=0,009)$, while the Frustration Tolerance score correlated positively with the percentage of motor partial seizure reduction $(\mathrm{r}=0,45 ; \mathrm{p}=0,042)$. In other words, both Neuroticism and Frustration Tolerance, seem to be predictors of favorable treatment response for partial seizures, and sensory and motor partial seizures in particular.

Nevertheless, the statistically significant correlations with the reduction of complex partial seizures have not been obtained. Similarly, no statistically significant correlations have been revealed for the reduction of primary generalized seizures, secondary generalized seizures and myoclonic seizures.

On the next stage of study an attempt to find possible relationships between complex of pre-morbid features and treatment results has been made, since every person is characterized by interaction of several personality traits. In other words, a hypothesis has been suggested that complex of pre-morbid personality traits would be valid enough to predict the degree of seizure reductions or remission length. For this purpose the regression analysis has been used, since it can reveal the dependence of one variable on several independent ones [28,29].

The main findings of this part of study are represented in Table 3. In this table are included the interactions (combinations) of different pre-morbid personality constructs related to the different final scores of treatment, i.e. the percentage of different type seizure reduction and the length of remission. In addition, the values of final overall correlation $(\mathrm{R})$, as the values of mutual variances $\left(\mathrm{R}^{2}\right)$ between independent and dependent variables are also included. It should be pointed out, that $\mathrm{R}^{2}$ level is thought to be the principal one in the assessment of predictive power of obtained regression equations, and its values may vary from 0 ( the lack of relationship at all) to the 1 (the functional relationship between independent and dependent variables).

Here can be seen, that the maximal value of $\mathrm{R}^{2}$ has been observed in regression for percentage of reduction of motor partial seizures $\left(R^{2}=0,57\right)$, for sensory partial seizures $\left(R^{2}=0,46\right)$, for sum of all types of partial seizures $\left(R^{2}=0,26\right) R^{2}$ and for primary generalized $R^{2}$ seizures $\left(R^{2}=0,25\right)$. In the other dependent variables the values of $R^{2}$ were much smaller or were near to zero. 
Results of this part of study revealed, that the high Neuroticism level is important for prediction of all partial seizure reduction. Besides, the high level of Neuroticism and Extraversion are important for the reduction of sensory partial seizures, while the high level of Frustration Tolerance and Esoteric Tendencies are important for reduction of motor partial seizures.

Alexithymia had unfavorable prognostic significance for prediction of remission length and reduction of seizures of all semiotics, although the values of $R^{2}$ were too small (0,07 and 0,05 respectively). Based upon these data the role of alexithymia should not be exaggerated.

Similarly, Rigidity had also negative prognostic significance for reduction of secondary generalized seizures, but could predict only $11 \%$ of response results.

\section{Discussion}

The current study rather seems to be the first one in which an attempt has been made to connect some pre-morbid personality variables in patients with epilepsy with results of antiepileptic drugs treatment.

The role and significance of pre-morbid personality characteristics in psychiatry are more properly understood and widely known opinion exists, that open extravert persons are usually characterized by better outcome and treatment responses in depression and schizophrenia [1822]. In epileptology such approach has not been approved yet.

Nevertheless, in the current study the preliminary promising results have been obtained that could confirm the role of pre-morbid personality structure in the prediction of treatment results irrespective of used AED in patients with epilepsy.

Obtained results have shown that several personality constructs are important for predicting in outcome results of treatment. These results concern as the remission length, reduction of all seizures, as seizure reduction of concrete semiotics.

Thus, alexithymia has appeared to be a basic and global characteristic that was negatively correlated as with remission duration, as with reduction of all seizures irrespective their semiotics. In this context suggestion can be made, that normal interrelationship between two hemispheres seems to be a prerequisite for favorable outcome of drug efficacy irrespective of used AEDs, since alexithymia as has been suggested may be caused by blockade between two hemispheres $[28,29]$. Nevertheless, the correlation between alexithymia and mentioned treatment outcome variables was too weak to make any definite and concrete statements about expected treatment results. In this context a suggestion can be proposed that combination of alexithymia with some neurobiological variables in patients with epilepsy could improve the prediction preciseness, although it must be proved in special trial.

Here should be stressed, that alexithymia is thought to represent rather the single personality construct for which the possible explanation in terms of neuropsychological mechanisms exists [28,29]. A priori it could help us to understand the mechanisms of treatment process more properly. That is why, despite a weak relationships between alexihymia and treatment results this personality construct shouldn't be rejected from the further study.

The other personality constructs (except of Rigidity) as a rule were included in regression equation with positive loadings. Among them Neuroticism has been included in two regressions for the assessment of percentage of reduction of all partial and sensory partial seizures. Such finding seems to be unexpected, since Neuroticism per se implies the predisposition to anxiety and depressive states development [20-22]. Obtained results may be interpreted in such sense that predisposition to neurotic states is favorable for the reduction of all partial and sensory partial seizures, in particular. In other words, a certain biological antagonism between neurotic predisposition and partial epilepsy may be suggested, although the mechanism of such antagonism remains unknown. Obviously the further studies are required to confirm or reject this assertion, which still remains as speculative one.

Along with Neuroticism in regression for the reduction of partial sensory seizures the Extraversion construct with positive loading has also been included. It implies the favorable prognostic significance both of personality constructs in prediction of sensory partial seizures reduction. Obviously, the combination of these two constructs in premorbid period seems to be a prerequisite of good response of sensory partial seizures to antiepileptic treatment.

Another combination consisting of Frustration Tolerance and Esoteric Tendencies was favorable for the reduction of motor partial seizures. It means that epileptic patients with high capability to cope with unpleasant life events and with esoteric interests and believes can show a good response of motor partial seizures to antiepileptic treatment.

Here should be stressed, that in our previous works the opposite relationship between alexithymia, on one side, and extraversion and frustration tolerance, on the other side, has been obtained [32,33]. That concerned the role of these constructs in the development of comorbid psychopathology i.e. depression and anxiety states in patients with partial forms of epilepsy. Alexithymia is thought to be risk factor for the development of depression and anxiety, while extraversion and frustration tolerance, on contrary, prevent appearance of such pathology. Interestingly, that alexithymia caused the maximal effect in epileptic patients with dominant left hand, while extraversion and frustration tolerance could prevent the appearance of co-morbid psychopathology mainly in the right-handed persons [32,33].

Principally, that rather antagonistic relationship between Alexithymia and Extraversion, Neuroticism and Frustration Tolerance was confirmed in the current study in relation to efficacy of AED treatment.

Unfortunately, the so-called neuropsychological basis of Neuroticism, Extraversion, Frustration Tolerance and Esoteric Tendencies remains still unknown, and robust conception that could explain obtained relationships is absent. Nevertheless, suggestion may be made, that further trial on the possible connection between personality traits, some neurobiological and basic characteristic of epilepsy and treatment response could help us to understand more properly the neuropsychological mechanisms not only epilepsy, but neurobiological essence of mentioned personality features.

\section{References}

1. Elwes RD, Johnson AL, Shorvon SD, Reynolds EH (1984) The prognosis for seizure control in newly diagnosed epilepsy. N Engl J Med 311: 944-947.

2. Hart YM, Sander JW, Johnson AL, Shorvon SD (1990) National General Practice Study of Epilepsy: recurrence after a first seizure. Lancet 336: 1271 1274.

3. Hauser WA, Rich SS, Annegers JF, Anderson VE (1990) Seizure recurrence after a 1st unprovoked seizure: an extended follow-up. Neurology 40: 11631170 .

4. Hauser WA, Rich SS, Lee JR, Annegers JF, Anderson VE (1998) Risk of recurrent seizures after two unprovoked seizures. N Engl J Med 338: 429-434.

5. Semah F, Picot MC, Adam C, Broglin D, Arzimanoglou A, et al. (1998) Is 
Citation: Kalinin VV, Zemlyanaya AA, Zheleznova EV, Sokolova LV (2015) Personality Variables in Prediction of Control over Seizures in Patients with Partial Epilepsies. Int J Neurorehabilitation 2: 137. doi:10.4172/2376-0281.1000137

the underlying cause of epilepsy a major prognostic factor for recurrence? Neurology 51: 1256-1262.

6. Kwan P, Brodie MJ (2000) Early identification of refractory epilepsy. N Engl J Med 342: 314-319.

7. Löscher W (2008) Current knowledge on basic mechanisms of drug-resistance. In: Drug-resistant epilepsies (Eds. P. Kahane, A. Berg, W. Loscher, D. Nordli, E. Perucca), John Libbey Eurotext 47-61.

8. Löscher W (2005) Mechanisms of drug resistance. Epileptic Disord 7: S3-S9.

9. Perucca E (2005) Can drug resistance in epilepsy be minimized? Challenging commonly held beliefs. Epileptic Disord 7 Suppl 1: S14-21.

10. Sander JW (1993) Some aspects of prognosis in the epilepsies: a review. Epilepsia 34: 1007-1016.

11. Schmidt D, Löscher W (2005) Drug resistance in epilepsy: putative neurobiologic and clinical mechanisms. Epilepsia 46: 858-877.

12. Semah F, Ryvlin $P(2005)$ Can we predict refractory epilepsy at the time of diagnosis? Epileptic Disord 7 Suppl 1: S10-13.

13. Arzimanoglou A, Ryvlin P (2008) Towards a clinically meaningful definition of drug-resistance. In: Drug-resistant epilepsies (Eds. P. Kahane, A. Berg, W. Loscher, D. Nordli, E. Perucca), John Libbey Eurotext 1-6.

14. Brodie MJ (2008) Are drug-resistant and drug-sensitive patients the same? Observations from the Glasgow database. In: Drug-resistant epilepsies (Eds. P. Kahane, A. Berg, W. Loscher, D. Nordli, E. Perucca), John Libbey Eurotext 17-27.

15. Sander JW (1993) Some aspects of prognosis in the epilepsies: a review. Epilepsia 34: 1007-1016.

16. Mattson RH, Cramer JA, Collins JF (1996) The Department of Veterans Affairs Epilepsy Cooperative Studies No.118 and No.264 Group. Prognosis for total control of complex partial and secondarily generalized tonic-clonic seizures. Neurology 47: 68-76.

17. Kalinin VV, ZemlyanayaAA, Zheleznova EV, Sokolova LV (2013) Neurobiological and clinical predictors of remission and antiepileptic treatment efficacy in partial epilepsies. J Epileptology, 21: 23-33.

18. Marneros A, Deister A, Rohde A (1992) Prämorbide und postmorbide Persönlichkeitsmerkmale bei Patienten mit idiopathischen Psychosen. In Marneros A., Philipp M.(eds.). Persönlichkeit und Psychische Erkrankung. Springer-Verlag, Berlin 87-100.

19. Möller H-J (1992) Zur Bedeutung und methodischen Problematik der psychiatrischen Persönlichkeitsforschung: der Typus melancholicus und andere Konzepte zur prämorbiden Persönlichkeit von Patienten mit affektiven Psychosen. In: Marneros A., Philipp M.(eds.). Persönlichkeit und Psychische Erkrankung. Springer-Verlag, Berlin 45-65.
20. Zerssen D (1969) von. Objektivirende Untersuchungen zur prämorbiden Persönlichkeit endogenen Depressiver (Methodik und vorläufig Ergebnisse) In: Hippius H., Selbach H. (eds.). Das depressive Syndrom. Urban und Schwarzenberg, München 183-205.

21. Zerssen D (1982) von. Personality and affective disorders. In: Paykel E.S. (eds.) Handbook of Affective Disorders. Churchill Livingstone, Edinburgh 212228

22. von Zerssen D, Pfister H, Koeller DM (1988) The Munich Personality Test (MPT)--a short questionnaire for self-rating and relatives' rating of personality traits: formal properties and clinical potential. Eur Arch Psychiatry Neurol Sci 238: 73-93.

23. Eysenck HJ, Eysenck SBG (1975) Manual of the Eysenck Personality Inventory London, Hodder \& Stoughton.

24. Tellenbach H (1971) Melancholie. Problemgeschichte, Endogenität, Typologie, Pathogenese, Klinik, 3. Auflage, Springer, Berlin.

25. Kretschmer E (1977) Körperbau und Charakter, 26 Auflage, Springer-Verlag Berlin.

26. Bagby RM, Taylor GJ, Ryan D (1986) Toronto Alexithymia Scale: relationship with personality and psychopathology measures. Psychother Psychosom 45 207-215.

27. Bagby RM, Taylor GJ, Parker JD, Loiselle C (1990) Cross-validation of the factor structure of the Toronto Alexithymia Scale. J Psychosom Res 34: 47-51.

28. Hoppe KD, Bogen JE (1977) Alexithymia in twelve commissurotomized patients. Psychother Psychosom 28: 148-155.

29. Lumley MA, Sielky K (2000) Alexithymia, gender, and hemispheric functioning Compr Psychiatry 41: 352-359.

30. Feinstein AR (2002) Principles of medical statistics. Boca Raton, Chapman\&Hall / CRC 701.

31. Mathews DE, Farewell VT (2007) Using and Understanding Medical Statistics, Basel, Karger 322

32. Kalinin VV, Zemlyanaya AA, Krylov OE, Zheleznova EV (2010) Handedness alexithymia, and focus laterality as risk factors for psychiatric comorbidity in patients with epilepsy. Epilepsy Behav 17: 389-394.

33. Kalinin VV, Zemlyanaya AA, Zheleznova EV, Krylov OE (2012) Premorbid Personality Traits, Focus Lateralization and Handedness as Risk Factors for Co-Morbid Affective and Anxiety Disorders in Temporal Lobe Epilepsy // Horizons in Neuroscience Research, Volume 7/Eds. Andres Costa and Eugenio Villalba, Nova Publishers, 2012- pp. 175-190. 